\title{
Preference for using posts to restore endodontically treated teeth: findings from a survey with dentists
}

Rafael SARKIS-ONOFRE(a) Tatiana PEREIRA-CENCI(a) Niek Johannes OPDAM ${ }^{(b)}$ Flávio Fernando DEMARCO(a)

(a) Federal University of Pelotas - UFPel, School of Dentistry, Graduate Program in Dentistry, Pelotas, RS, Brazil.

(b)Radboud University Nijmegen Medical Centre, Department of Restorative and Preventive Dentistry, Nijmegen, The Netherlands.

Declaration of Interests: The authors certify that they have no commercial or associative interest that represents a conflict of interest in connection with the manuscript.

Corresponding Author:

Tatiana Pereira-Cenci

E-mail: tatiana.dds@gmail.com

DOI: 10.1590/1807-3107BOR-2015.vol29.0001

Submitted: May 21, 2014

Accepted for publication: Aug 02, 2014

Last revision: Sep 30, 2014

\begin{abstract}
The aim of this study was to evaluate if clinical experience, whether in relation to length of practice time and/or level of specialization influences the dentist's preference for using posts to restore endodontically treated teeth. A cross sectional study was carried out using a questionnaire with dentists $(n=276)$ in Pelotas, southern Brazil. Data were collected regarding clinical experience, post-graduate training, and variables related to restorations (posts/cements and use of rubber $\mathrm{dam}$ ) for endodontically treated teeth. The data were submitted to a descriptive analysis and associations were tested. The response rate was $68 \%$. Cast metal posts $(24.53 \%)$, glass fiber posts $(20.75 \%)$ and resin cement $(66.67 \%)$ were the most commonly selected materials. In relation to rubber dams, $93.05 \%$ of the dentists were found not use them to lute posts. There was a significant association between the level of training of post-graduate dentists and the type of post used ( $p=0.027)$, in that dentists without post-graduate training used cast metal posts more frequently, whereas dentists with post-graduate training reported glass fiber posts as their first choice. The results of the study showed that dentists preferred cast metal posts, glass fiber posts and resin cement. Continuing education influenced the decision of the dentists on their choice of dental posts.
\end{abstract}

Keywords: Tooth, Nonvital; Decision Making; Dental Restoration, Permanent.

\section{Introduction}

Endodontically treated teeth (ETT) may have signs of large coronal destruction resulting from aggressive endodontic treatment, caries or trauma. In these cases, intraradicular posts may be necessary to improve retention of the restorative material to the root portion. ${ }^{1} \mathrm{~A}$ wide range of post and cement types are available on the market for restoring ETT. Procedures vary from using a conventional cast metal post and core to adopting a one-visit technique using commercially available prefabricated post systems. ${ }^{2,3,4,5}$ Factors related to posts, such as material, esthetics, design, luting techniques, and factors related to teeth, such as remaining coronal structure, presence of ferrule and root length, have been seen to influence post selection and survival of these restorations. ${ }^{6,7,8,9}$

Furthermore, the literature has shown that factors related to dentists can also influence the decision-making process, specifically in regard 
to clinical experience and post-graduate training. ${ }^{10}$ The skills of a dentist can be improved over time in clinical practice. However, the introduction of new materials on the market requires training and updated knowledge by dentists, to ensure the best application of these new materials. ${ }^{10,11,12,13,14}$ The dentists' preference for materials and techniques, and their level of knowledge regarding the proper use of these materials, are investigatory avenues of interest that could be adopted to guide undergraduate dental curricula and continuing education courses.

In recent years, greater interest has been seen in the Dental Practice Based Research approach, where the preferences of dentists are taken into consideration and the treatments are evaluated in a "real world" clinical practice scenario. ${ }^{15,16}$ This way of associating knowledge with scientific interpretation has been considered the best method, and can be implemented directly and quickly in regular clinical practice. ${ }^{17}$

The present study was designed to evaluate the preferences of dentists for the materials chosen to restore ETT, and the influence of both clinical experience (time since graduation) and level of specialization (post-graduate training) on the dentist's choice of posts.

\section{Methodology}

This cross sectional study was approved by the Local Ethics Committee (116/2009) and carried out between March and June 2009, in Pelotas, in the southern region of Brazil. All dentists registered at the local division of the Regional Council of Dentistry $(n=276)$ were invited to participate in the study. Data were collected through a self-applied closed questionnaire. The following information was gathered: social-demographic characteristics, clinical experience (time since graduation, in years and categorized as $\leq 10$ years, 11-20 years, and $>20$ years), post-graduate training (none, specialization level, Master's or PhD degree, and dichotomized into none and specialist). Information about the use of posts to restore ETT was collected as follows: most frequently used post (cast metal, pre-fabricated metal, carbon fiber, glass fiber, more than 1 or none), the resin cement used to lute these posts (glass ionomer cement, resin cement, both or none) and the use of a rubber dam (yes or no).

First, the questionnaire was pre-tested with professionals not involved in the study, from a city with characteristics similar to those of Pelotas. The data collected did not allow any information to be included that could identify the dentist. The questionnaire was given personally at each dentist's clinic, and the information about the study and its importance were explained. The questionnaire was collected together with the signed informed consent a week later. If the dentist did not return the questionnaire after 2 visits, his/her participation was eliminated. Further information about this methodology has been published elsewhere. ${ }^{10,14}$

Data were submitted to descriptive analyses, and the existing association between post-graduate training, clinical experience and dentist preferences (type of post/cement and use of rubber dam) were assessed according to Fisher's exact test. The analyses were carried out with Stata 10.0 software (StataCorp, College Station, USA). A significance level of $\alpha=0.05$ was considered.

\section{Results}

Of the total 276 dentists invited to participate in the study, 187 (68\%) answered the questionnaire. Those eliminated were mainly due to their not retuning the questionnaire $(n=48)$ or not signing the informed consent $(n=32)$, but there were also some refusals $(\mathrm{n}=9)$. Since the questionnaire was self-applied, some of the dentists missed some questions; this is why the number of answers varied for each question.

Descriptive analysis showed that $52.4 \%$ of the dentists were female and $96 \%$ classified themselves as white. The average time since graduation was $\geq 10$ years $(53.2 \%)$ and $64.7 \%$ of the dentists had some degree of post-graduate training.

Table 1 shows that cast metal posts (24.5\%) and glass fiber posts $(20.8 \%)$ were the most commonly used type of intra-radicular post. Analyzing the group of pre-fabricated posts (metal, carbon fiber and glass fiber), there was a trend to use these instead cast metal posts. Regarding the type of cement, resinbased cement was selected by $66.7 \%$ of the dentists and non-use of a rubber dam was reported by $93.1 \%$ of the dentists. 
Table 1. Number of observations and frequencies of the variables studied, among dentists.

\begin{tabular}{lcc}
\hline Variable & $\mathrm{n}^{*}$ & $\%(95 \% \mathrm{Cl})$ \\
\hline Type of Post & 159 & \\
Cast Metal Post & 39 & $24.53(18.0-32.0)$ \\
Pre-fabricated Metal Post & 28 & $17.61(12.0-24.4)$ \\
Carbon Fiber Post & 7 & $4.40(1.8-8.9)$ \\
Glass Fiber Post & 33 & $20.75(14.7-27.9)$ \\
More than 1 & 17 & $10.69(6.4-16.6)$ \\
None & 35 & $22.01(15.8-29.3)$ \\
Type of Cement & 111 & \\
Glass lonomer Cement & 31 & $27.93(19.8-37.2)$ \\
Resin Cement & 74 & $66.67(57.1-75.3)$ \\
Both & 6 & $5.41(2.0-11.4)$ \\
Rubber Dam Use & 187 & \\
No & 174 & $93.05(88.4-96.2)$ \\
Yes & 13 & $6.95(3.7-11.6)$ \\
\hline
\end{tabular}

The results in Table 2 did not show a significant association between time since graduation and type of post/cement preference and use of a rubber dam. However, there was a trend for dentists with less time since graduation to use glass fiber posts and rubber dams to lute posts more frequently than dentists with a longer time since graduation. Table 3 shows a significant association between the training of post-graduate dentists and the type of post selected $(p=0.027)$. Dentists without post-graduate training were seen to use cast metal posts more frequently, whereas dentist with post-graduate training reported using glass fiber posts as their first choice.

\section{Discussion}

This study is the first survey among Brazilian dentists to analyze the preferences of clinicians for several aspects related to the of use intra-radicular posts. The findings of this study are important, since surveys based on questionnaires provide important information about demographics, attitudes, opinions, and the approach toward treatment. ${ }^{18}$ The study showed that dentists preferred cast metal posts and glass fiber posts to restore endodontically treated teeth. The literature has shown that metal posts and glass fiber posts present different mechanical properties. Metal posts have a high elastic modulus, in comparison with that of dentin. This could increase the risk of root fracture and catastrophic failure, ${ }^{19}$ whereas glass fiber posts have mechanical properties similar to those of dentin, thus reducing the risk of catastrophic failure and consequent failures related to their use, mostly involving post debonding. ${ }^{1,9}$

Two systematic reviews available in the literature show that there is no evidence to support the "best

Table 2. Association between length of clinical practice time (time since graduation) and variables related to post use.

\begin{tabular}{|c|c|c|c|c|c|}
\hline \multirow{2}{*}{ Variable } & \multicolumn{5}{|c|}{ Time since graduation in years [ $\mathrm{n}(\%)]$} \\
\hline & $0-9$ years & 10-11 years & $>20$ years & Total & $p$-value \\
\hline Type of Post & & & & & 0.644 \\
\hline Cast Metal Post & $20(52.3)$ & $9(23.68)$ & $9(23.68)$ & $38(100)$ & \\
\hline Pre-fabricated Metal Post & $15(53.57)$ & $4(14.29)$ & $9(32.14)$ & $28(100)$ & \\
\hline Carbon Fiber Post & $1(14.29)$ & $3(42.86)$ & $3(42.86)$ & $7(100)$ & \\
\hline Glass Fiber Post & $18(54.55)$ & $4(12.12)$ & $11(33.33)$ & $33(100)$ & \\
\hline More than 1 & $4(23.53)$ & $6(35.29)$ & $7(41.18)$ & $17(100)$ & \\
\hline None & $20(57.14)$ & $8(22.86)$ & $7(20.00)$ & $35(100)$ & \\
\hline Type of Cement & & & & & 0.108 \\
\hline Glass lonomer Cement & $15(50)$ & $7(23.33)$ & $8(26.67)$ & $30(100)$ & \\
\hline Resin Cement & $37(50)$ & $14(18.92)$ & $23(31.08)$ & $74(100)$ & \\
\hline Both & $0(0)$ & $3(50)$ & $3(50)$ & $6(100)$ & \\
\hline Rubber Dam Use & & & & & 0.466 \\
\hline No & 78 (45.09) & 39 (22.54) & $56(32.37)$ & $173(100)$ & \\
\hline Yes & 7 (53.85) & $4(30.77)$ & $2(15.38)$ & $13(100)$ & \\
\hline
\end{tabular}


Table 3. Association between post-graduate training of dentists and variables related to post use.

\begin{tabular}{lccc}
\hline Variable & Post-graduate & Training $[\mathrm{n}(\%)]$ & Total \\
\cline { 2 - 3 } $\begin{array}{l}\text { Type of Post } \\
\text { Cast Metal Post }\end{array}$ & No & Yes & \\
Pre-fabricated Metal Post & $20(52.63)$ & $18(47.37)$ & $38(100)$ \\
Carbon Fiber Post & $12(42.86)$ & $16(57.14)$ & $28(100)$ \\
Glass Fiber Post & $1(16.67)$ & $5(83.33)$ & $6(100)$ \\
More than 1 & $14(42.2)$ & $19(57.8)$ & $33(100)$ \\
None & $8(47.06)$ & $9(52.94)$ & $17(100)$ \\
Type of Cement & $6(17.14)$ & $29(82.6)$ & $35(100)$ \\
Glass lonomer Cement & & & $31(100)$ \\
Resin Cement & $13(41.94)$ & $18(58.06)$ & $72(100)$ \\
Both & $31(43.06)$ & $69(56.94)$ & $6(100)$ \\
Rubber Dam Use & $3(50.0)$ & $3(50.0)$ & $172(100)$ \\
No & & $110(63.95)$ & $13(100)$ \\
Yes & $62(36.05)$ & $10(76.92)$ & 0.548 \\
\hline
\end{tabular}

way" to restore endodontically treated teeth. ${ }^{20,21} \mathrm{~A}$ recent study comparing the use of glass fiber posts versus cast metal posts, in teeth with no remaining coronal wall, showed that no difference was found between the groups using these two types of posts, after up to 3 years of follow-up. ${ }^{5}$ However, several factors must be borne in mind when choosing the post to be used in restoring ETT, including remaining coronal structure, presence of ferrule and post material. ${ }^{1}$ Greater tooth survival is ensured when at least one wall is maintained, even in ETT. ${ }^{22}$ In addition, it has been shown that the presence of ferrule (minimum $2 \mathrm{~mm}$ ) is a decisive factor for the success of cast post and core. ${ }^{23}$ With regard to post material, metal posts have a high elastic modulus, in comparison with that of dentin, and could therefore increase the risk of root fracture and catastrophic failure, ${ }^{19}$ whereas glass fiber posts were introduced as an alternative to metal posts, and show mechanical properties similar to those of dentin. ${ }^{19}$

Most dentists preferred resin-based cements to lute posts. The use of glass ionomer cements to lute posts seems to be a less sensitive technique; however, a combination of the etch-and-rinse adhesive system and regular resin cement is the most commonly used approach in restorative dentistry, specifically to lute glass fiber posts (GFPs). ${ }^{24}$ In the past decade, self-adhesive resin cements were introduced to provide easier clinical application, compared with regular resin cements. ${ }^{25}$ A recent systematic review of in vitro studies showed that the literature on these studies suggests that self-adhesive resin cement could improve the retention of GFPs into root canals. ${ }^{26}$ However, an important limitation of the present study is related to the issue of cement choice, since no option was given for zinc phosphate cement. This must be emphasized, since zinc phosphate cements are widely used, especially to lute cast metal posts, because of their long history of success, as well as their lower price and less sensitive technique, compared with resin cements. ${ }^{27}$ Additionally, it may be said that the use of glass fiber posts may also be related to the experience of clinicians with resin cements, while when no experience is considered, dentists tend to avoid the use of resin based cements and use zinc phosphate.

Considering post-graduate training, the literature seems to suggest that dental specialists are more familiar with the literature and participate in meetings with greater frequency, directly influencing their clinical choices and, consequently, their practices. These dentists are also more prepared to introduce new technologies in their clinical practice..$^{10,11,12,13,14}$ Our results show that dentists with post-graduate 
training tend to prefer glass fiber posts as their first choice to restore ETT, whereas non-specialists tend to prefer cast metal posts. In a survey with 909 American dentists, the different philosophies and techniques for restoring ETT varied significantly depending on the dentist's geographic region, age, faculty status, and specialty status. ${ }^{28}$ Furthermore, pre-fabricated posts are more popular among dentists than cast metal posts. A survey with 6,029 dentists from Germany showed the same trend in preferring pre-fabricated posts. ${ }^{29}$ One of the most important advantages of these posts is that there is no need for a laboratorial step, unlike cast metal posts, and that they can be applied using a one-visit technique. In the current scientific literature, several clinical trials have shown good clinical performance for pre-fabricated posts. ${ }^{2,3,4,5}$

Another important issue is the use of rubber dam isolation. A recent study ${ }^{30}$ evaluated the influence of using a rubber dam during post placement for the success of root-canal-treated teeth. A retrospective chart review of 185 patients showed that the success rate of the underlying endodontic treatment was significantly enhanced when a rubber dam was used. This result is important, since most dentists in the present study reported not using rubber dams

\section{References}

1. Fernandes AS, Shetty S, Coutinho I. Factors determining post selection: a literature review. J Prosthet Dent. 2003 Dec;90(6):556-62.

2. Fokkinga WA, Kreulen CM, Bronkhorst EM, Creugers NH. Up to 17-year controlled clinical study on post-and-cores and covering crowns. J Dent. 2007 Oct;35(10):778-86.

3. Piovesan EM, Demarco FF, Cenci MS, Pereira-Cenci T. Survival rates of endodontically treated teeth restored with fiber-reinforced custom posts and cores: a 97-month study. Int J Prosthodont. 2007 Nov-Dez;20(7):633-39.

4. Naumann M, Koelpin M, Beuer F, Meyer-Lueckel H. 10-year survival evaluation for glass-fiber-supported postendodontic restoration: a prospective observational clinical study. J Endod. 2012 Apr;38(4):432-35.

5. Sarkis-Onofre R, Jacinto RC, Boscato N, Cenci MS, PereiraCenci T. Cast metal vs. glass fibre posts: a randomized controlled trial with up to 3 years of follow up. J Dent. 2014 May;42(5):582-7. Epub ahead of print.2014 Feb 12.

6. Goracci C, Ferrari M. Current perspectives on post systems: a literature review. Aust Dent J. 2011 Jun;56(1 Suppl):77-83. to lute posts, even though they were taught to use rubber dams to lute glass fiber posts in dental school. However, this does not seem to be a common practice in clinical situations.

This study has some limitations, since it was based on a self-applied closed questionnaire. Some disadvantages include the fact that self-application requires another visit by the research staff, and the interviewee does not always answer all the questions of the questionnaire. The response rate was $68 \%$, which can be considered high in comparison with another German survey in the same field. ${ }^{29}$

\section{Conclusion}

In conclusion, the results of the study showed that dentists preferred cast metal and glass fiber posts cemented with resin-based cement to restore ETT. Continuing education was a factor influencing the decisions on the choice of dental posts.

\section{Acknowledgements}

The authors would like to thank all the dentists for their participation in this study and Amália Bielemann, Thiago Ribeiro and Vinícius Sommer for delivering the questionnaires.

7. Faria-e-Silva AL, Mendonça AA, Garcez RM, Oliveira AS, Moreira AG, Moraes RR. Adhesion strategy and early bond strengths of glass-fiber posts luted into root canals. Braz Oral Res. 2012 Sep-Oct;26(5):485-7.

8. Faria-e-Silva AL, Menezes MS, Silva FP, Reis GR, Moraes RR. Intra-radicular dentin treatments and retention of fiber posts with self-adhesive resin cements. Braz Oral Res. 2013 Jan-Feb;27(1):14-9.

9. Santos Filho PC, Soares PV, Reis BR, Veríssimo C, Soares CJ. Effects of threaded post placement on strain and stress distribution of endodontically treated teeth. Braz Oral Res. 2013 Jul-Aug;27(4):305-10.

10. Nascimento GG, Correa MB, Opdam N, Demarco FF. Do clinical experience time and postgraduate training influence the choice of materials for posterior restorations? Results of a survey with Brazilian general dentists. Braz Dent J. 2013 Nov-Dec;24(6):642-6.

11. Brunthaler A, König F, Lucas T, Sperr W, Schedle A. Longevity of direct resin composite restorations in posterior teeth. Clin Oral Investig. 2003 Jun;7(2):63-70. 
12. Burke FJ, Lucarotti PS, Holder R. Outcome of direct restorations placed within the general dental services in England and Wales (Part4): influence of time and place.J Dent. 2005 Nov;33(10):837-47.

13. Demarco FF, Corrêa MB, Cenci MS, Moraes RR, Opdam NJ. Longevity of posterior composite restorations: not only a matter of materials. Dent Mater. 2012 Jan;28(1):87-101.

14. Demarco FF, Baldissera RA, Madruga FC, Simões RC, Lund $\mathrm{RG}$, Correa MB, et al. Anterior composite restorations in clinical practice: findings from a survey with general dental practitioners. J Appl Oral Sci. 2013 Nov-Dec;21(6):497-504.

15. Horn SD, Gassaway J. Practice-based evidence study design for comparative effectiveness research. Med Care. 2007 Oct;45(10 Suppl 2):50-7.

16. Opdam NJ, Roeters JJ, Loomans BA, Bronkhorst EM. Sevenyear clinical evaluation of painful cracked teeth restored with a direct composite restoration. J Endod. 2008 Jul;34(7):808-11.

17. Gilbert GH, Richman JS, Gordan VV, Rindal DB, Fellows JL, Benjamin PL, et al; DPBRN Collaborative Group. Lessons learned during the conduct of clinical studies in the dental PBRN. J Dent Educ. 2011 Apr;75(4):453-65.

18. Tortopidis D, Papa P, Menexes G, Koidis P. Attitudes of dentists regarding the restoration of root canal treated teeth: a survey in Greece. Int Dent J. 2010 Oct;60(5):336-42.

19. Zarone F, Sorrentino R, Apicella D, Valentino B, Ferrari M, Aversa R, et al. Evaluation of the biomechanical behavior of maxillary central incisors restored by means of endocrowns compared to a natural tooth: a 3D static linear finite elements analysis. Dent Mater. 2006 Nov;22(11):1035-44.

20. Fedorowicz Z, Carter B, Souza RF, Chaves CAL, Nasser M, Sequeira-Byron $P$. Single crowns versus conventional fillings for the restoration of root filled teeth. Cochrane Database Syst Rev. 2012 May 16;5:CD009109. DOI: 10.1002/14651858.CD009109.pub2.

21. Bolla M, Muller-Bolla M, Borg C, Lupi-Pegurier L, Laplanche O, Leforestier E. Root canal posts for the restoration of root filled teeth. Cochrane Database Syst Rev. 2007 Jan 24;(1):CD004623.
22. Ferrari M, Vichi A, Fadda GM, Cagidiaco MC, Tay FR, Breschi $\mathrm{L}$, et al. A randomized controlled trial of endodontically treated and restored premolars. J Dent Res. 2012 Jul:91(7 Suppl);72-8.

23. Silva NR, Raposo LH, Versluis A, Fernandes-Neto AJ, Soares CJ. The effect of post, core, crown type, and ferrule presence on the biomechanical behavior of endodontically treated bovine anterior teeth. J Prosthet Dent. 2010 Nov;104(5):306-17.

24. Rasimick BJ, Wan J, Musikant BL, Deutsch AS. A review of failure modes in teeth restored with adhesively luted endodontic dowels. J Prosthodont. 2010 Dec;19(8):639-46

25. Ferracane JL, Stansbury JW, Burke FJ. Self-adhesive resin cements-Chemistry, properties and clinical considerations. J Oral Rehabil. 2011 Apr:38(4);295-314.

26. Sarkis-Onofre R, Skupien JA, Cenci MS, Moraes RR, Pereira-Cenci $\mathrm{T}$. The role of resin cement on bond strength of glass-fiber posts luted into root canals: a systematic review and meta-analysis of in vitro studies. Oper Dent. 2014 Jan-Feb;39(1):31-44.

27. Farid F, Mahgoli H, Hosseini A, Chiniforush N. Effect of eugenol-containing and resin endodontic sealers on retention of prefabricated metal posts cemented with zinc phosphate and resin cements. J Prosthodont Res. 2013 Oct;57(4):284-87.

28. Morgano SM, Hashem AF, Fotoohi K, Rose L. A nationwide survey of contemporary philosophies and techniques of restoring endodontically treated teeth. J Prosthet Dent. 1994 Sep;72(3):259-67.

29. Naumann M, Kiessling S, Seemann R. Treatment concepts for restoration of endodontically treated teeth: A nationwide survey of dentists in Germany. J Prosthet Dent. 2006 Nov;96(5):332-8.

30. Goldfein J, Speirs C, Finkelman M, Amato R. Rubber dam use during post placement influences the success of root canal-treated teeth. J Endod. 2013 Dec;39(12):1481-4. 